\title{
Induction of Apoptosis in Small-Cell Lung Cancer Cells by an Antisense Oligodeoxynucleotide Targeting the Bcl-2 Coding Sequence
}

\author{
Ziegler, A ; Luedke, G H ; Stahel, R A ; Zangemeister-Wittke, U ; Fabbro, D ; Altmann, K-H
}

\begin{abstract}
Background: The emergence of resistance to chemotherapy remains a major problem in the treatment of patients with small-cell lung cancer. Elevated expression of Bcl-2, a protein that inhibits programmed cell death or apoptosis, has been associated with radiation and drug resistance and has been observed in the majority of small-cell lung cancer specimens and cell lines. Purpose: To test the hypothesis that Bcl-2 expression levels are critical for inhibiting apoptosis in small-cell lung cancer cells, we used an antisense strategy to reduce Bcl-2 expression in these cells in an attempt to restore the natural occurrence of apoptosis. Methods: Thirteen antisense oligodeoxynucleotides (ODNs) targeting various regions of the bcl-2 messenger RNA and a control scrambledsequence ODN were tested to identify the most effective sequence(s) for reducing Bcl-2 protein levels. Northern and western blot analyses were used to examine basal bcl-2 messenger RNA and protein levels, respectively, in four human small-cell lung cancer cell lines (SW2, NCI-H69, NCI-H82, and NCI-N417). SW2 cells were treated with the antisense ODNs in the presence of cationic lipids (to facilitate uptake), and cytotoxic effects were measured by use of a cell viability assay. Flow cytometric analysis of DNA fragmentation and cell morphology was also performed. The cytotoxic effect of the most potent antisense ODN was also tested on the three other cell lines. Results: The viability of SW2 cells was effectively reduced by ODNs that targeted the translation initiation and termination sites of the bcl-2 messenger RNA, but ODN 2009 that targeted the coding region was the most cytotoxic. Treatment of SW2 cells with $0.15 \mu \mathrm{M}$ ODN 2009 for 96 hours reduced their viability by $91 \%$ (95\% confidence interval $[\mathrm{CI}]=88 \%-94 \%)$ and caused a dose-dependent reduction in Bcl-2 levels that became detectable 24 hours after treatment and persisted up to 96 hours; analysis of cellular morphology demonstrated that viability was reduced through apoptosis. Moreover, ODN 2009 at $0.15 \mu \mathrm{M}$ was cytotoxic to NCI-H69, NCI-H82, and NCI-N417 cells, resulting in decreases in cell viability of $82 \%(95 \% \mathrm{CI}=78 \%-86 \%), 100 \%$, and $100 \%$, respectively, after 96 hours of treatment. The cytotoxic effects were inversely correlated with the basal Bcl-2 levels in the cell lines $(\mathrm{r}=-.9964)$. A control scrambled-sequence oligodeoxynucleotide had no statistically significant effect on the cell lines $(\mathrm{P}$ values ranging from .38 to .89). Conclusion: We have identified a novel antisense ODN sequence (ODN 2009) that effectively reduces the viability of small-cell lung cancer cells by reducing Bcl-2 levels and facilitating apoptosis
\end{abstract}

DOI: https://doi.org/10.1093/jnci/89.14.1027

Posted at the Zurich Open Repository and Archive, University of Zurich

ZORA URL: https://doi.org/10.5167/uzh-155048

Journal Article

Published Version

Originally published at: 
Ziegler, A; Luedke, G H; Stahel, R A; Zangemeister-Wittke, U; Fabbro, D; Altmann, K-H (1997). Induction of Apoptosis in Small-Cell Lung Cancer Cells by an Antisense Oligodeoxynucleotide Targeting the Bcl-2 Coding Sequence. Journal of the National Cancer Institute, 89(14):1027-1036.

DOI: https://doi.org/10.1093/jnci/89.14.1027 


\title{
ARTICLES
}

\section{Induction of Apoptosis in Small-Cell Lung Cancer Cells by an Antisense Oligodeoxynucleotide Targeting the Bcl-2 Coding Sequence}

\author{
Annemarie Ziegler, Gerd H. Luedke, Doriano Fabbro, Karl-Heinz Altmann, \\ Rolf A. Stahel, Uwe Zangemeister-Wittke*
}

Background: The emergence of resistance to chemotherapy remains a major problem in the treatment of patients with small-cell lung cancer. Elevated expression of Bcl-2, a protein that inhibits programmed cell death or apoptosis, has been associated with radiation and drug resistance and has been observed in the majority of small-cell lung cancer specimens and cell lines. Purpose: To test the hypothesis that Bcl-2 expression levels are critical for inhibiting apoptosis in small-cell lung cancer cells, we used an antisense strategy to reduce Bcl-2 expression in these cells in an attempt to restore the natural occurrence of apoptosis. Methods: Thirteen antisense oligodeoxynucleotides (ODNs) targeting various regions of the bcl-2 messenger RNA and a control scrambledsequence ODN were tested to identify the most effective sequence(s) for reducing Bcl-2 protein levels. Northern and western blot analyses were used to examine basal bcl-2 messenger RNA and protein levels, respectively, in four human small-cell lung cancer cell lines (SW2, NCI-H69, NCI-H82, and NCI-N417). SW2 cells were treated with the antisense ODNs in the presence of cationic lipids (to facilitate uptake), and cytotoxic effects were measured by use of a cell viability assay. Flow cytometric analysis of DNA fragmentation and cell morphology was also performed. The cytotoxic effect of the most potent antisense ODN was also tested on the three other cell lines. Results: The viability of SW2 cells was effectively reduced by ODNs that targeted the translation initiation and termination sites of the bcl-2 messenger RNA, but ODN 2009 that targeted the coding region was the most cytotoxic. Treatment of SW2 cells with $0.15 \mu M$ ODN 2009 for 96 hours reduced their viability by $91 \%$ (95\% confidence interval $[\mathrm{CI}]=88 \%-94 \%$ ) and caused a dose-dependent reduction in Bcl-2 levels that became detectable 24 hours after treatment and persisted up to 96 hours; analysis of cellular morphology demonstrated that viability was reduced through apoptosis. Moreover, ODN 2009 at $0.15 \mu M$ was cytotoxic to NCI-H69, NCI-H82, and NCI-N417 cells, resulting in decreases in cell viability of $82 \%(95 \% \mathrm{CI}=\mathbf{7 8 \%}$ $86 \%$ ), $100 \%$, and $100 \%$, respectively, after 96 hours of treatment. The cytotoxic effects were inversely correlated with the basal Bcl-2 levels in the cell lines $(r=-.9964)$. A control scrambled-sequence oligodeoxynucleotide had no statisti- cally significant effect on the cell lines ( $P$ values ranging from .38 to .89). Conclusion: We have identified a novel antisense ODN sequence (ODN 2009) that effectively reduces the viability of small-cell lung cancer cells by reducing Bcl-2 levels and facilitating apoptosis. [J Natl Cancer Inst 1997;89:102736]

Lung cancer is the leading cause of cancer deaths in Western countries, and its incidence continues to rise worldwide (1). Small-cell lung cancer makes up about $25 \%$ of lung cancer cases and is characterized by a rapid and aggressive clinical course. After an initial response to chemotherapy, most small-cell lung cancers relapse in a drug-resistant form, leading to a 2-year survival of only $5 \%$ (1). Despite intensive research, improvements in the treatment of refractory small-cell lung cancer have remained elusive. Current efforts are directed toward the identification of novel genetic alterations in small-cell lung cancer and toward the understanding of mechanisms responsible for drug resistance. Among the latter, several genetic changes have been found in small-cell lung cancer that alter drug transport and activity (2), as well as defects that prevent apoptotic cell death after cytotoxic damage $(3,4)$.

The bcl-2 proto-oncogene (also known as BCL2) was first identified as a site involved in a $\mathrm{t}(14 ; 18)$ chromosomal translocation in follicular lymphomas (5). The Bcl-2 protein is localized in the endoplasmic reticulum, the outer mitochondrial membrane, and the nuclear envelope (6). Although its mechanism of action is still unclear, Bcl-2 functions as a suppressor of apoptotic death triggered by a variety of signals. Recent evidence (7) suggests that Bcl-2 contributes to cell survival also by diminishing the rate of cell proliferation. Furthermore, Bcl-2 was

*Affiliations of authors: A. Ziegler, G. H. Luedke, R. A. Stahel, U. Zangemeister-Wittke, University Hospital Zürich, Department of Internal Medicine, Division of Oncology, Switzerland; D. Fabbro, K.-H. Altmann, Novartis Pharma, Basel, Switzerland.

Correspondence to: Uwe Zangemeister-Wittke, Ph.D., University Hospital Zürich, Department of Internal Medicine, Division of Oncology, Häldeliweg 4, CH-8044 Zürich, Switzerland. E-mail: onkzang@usz.unizh.ch

See "Notes" following "References."

(C) Oxford University Press 
shown to prevent activation of the ICE protease cascade (8), and early experiments (9) demonstrated that it cooperates with the Myc oncoprotein to transform cells. Recently, a link has been established between expression of bcl-2 in tumors and certain forms of radiation and drug resistance. For instance, ectopic expression of bcl-2 in a neuroblastoma cell line that was bcl-2 negative by immunoprecipitation conferred resistance to cisplatinand etoposide-induced apoptosis (10), and comparable results were obtained by use of lymphocytic leukemia cell lines (11). In small-cell lung cancer, it has been estimated from immunohistochemical and western blot analyses that up to $90 \%$ of tumors (4) and cell lines (12) overexpress bcl-2. However, since the sensitivity of these assay systems is limited, it remains unclear whether Bcl-2-negative small-cell lung cancer cells really exist. The modulatory role of Bcl-2 in the response of small-cell lung cancers to chemotherapy has been demonstrated by transfection experiments analogous to those mentioned above: Ectopic expression of bcl-2 in a small-cell lung cancer cell line increased the resistance to apoptosis induced by chemotherapy (13). In view of the prevalence and protective function of Bcl-2, we hypothesized that Bcl-2 must be critical for inhibiting apoptosis in small-cell lung cancer cells.

This study was motivated by the lack of appropriate treatments for small-cell lung cancer, as well as the lack of data on the implication of up-regulated (i.e., increased) bcl-2 expression in small-cell lung cancer and solid tumors in general. To address these issues, we have used an antisense strategy to achieve down-regulation (i.e., a reduction) of bcl-2 expression in smallcell lung cancer cells. Similar approaches in other tumor models have resulted in decreased cell survival $(14,15)$, the induction of apoptotic death (16), and increased drug sensitivity in vitro and in vivo $(11,17)$. To investigate the issue of sequence dependence with respect to the effectiveness of antisense treatment, we tested 13 different antisense oligodeoxynucleotides (ODNs) targeting various regions of the bcl-2 messenger RNA for cytotoxicity on various small-cell lung cancer cell lines.

\section{Materials and Methods}

Cell lines and transfection. We studied the following four human small-cell lung cancer cell lines: SW2, NCI-N417, NCI-H82, and NCI-H69. All cell lines were cultured in RPMI-1640 medium (Life Technologies, Ltd. [GIBCO BRL], Paisley, U.K.) supplemented with $2 \mathrm{mM}$ L-glutamine, $10 \%$ fetal calf serum (FCS), $50 \mathrm{IU} / \mathrm{mL}$ penicillin, and $50 \mu \mathrm{g} / \mathrm{mL}$ streptomycin at $37^{\circ} \mathrm{C}$ in a humidified atmosphere with $5 \% \mathrm{CO}_{2}$. The SW2 cell line was obtained from the Dana-Farber Cancer Institute, Boston, MA; the NCI-N417, NCI-H82, and NCI-H69 cell lines were obtained from the American Type Culture Collection (ATCC), Rockville, MD. All cells were grown as floating aggregates.

Bcl-2 antisense ODNs. A total of 13 antisense ODNs targeting various regions of the bcl-2 messenger RNA were provided by Novartis Pharma, Basel, Switzerland. A BLASTN search of a database containing all sequences in the GenBank, European Molecular Biology Laboratory (EMBL) database, DNA Data Bank of Japan (DDBJ), and the Protein Data Bank (PDB) revealed no homology of the ODNs to other human genes except for ODN 2300. All ODNs were 20-mer (i.e., 20 nucleotides long) phosphorothioates purified by highpressure liquid chromatography. The sequences were as follows: 2291, 5'CGCCATCCTTCCCAGAGGAA-3'; 2292, 5' -CCAGCGTGCGCCATCCTTCC-3'; 2293, 5'-TCCCAGAGGAAAAGCAACGG-3'; 2294, 5'-TGCAGCTGGCTGGACATCTC-3'; 2009, 5'-AATCCTCCCCCAGTTCACCC-3'; 2295， 5'-TGTTGACTTCACTTGTGGCT-3'; 2011, 5' GGCAGGCATGTTGACTTCAC-3'; 2296， 5'-CCTTTTGCATATTTGTTTGG-3'；2297， 5'-TGCTTTAGTGAACCTTTTGC-3'; 2298, 5'-TGTTTCATGGTACATCACTG-3'; 2299, 5' -TGTTATTTTTTCTTAAA-
CAG-3'; 2300, 5'-TGTGTGTCTGTCTGTGTGTG-3'; and 2017, 5'GTAAATAGCTGATTCGACGT-3'.

The scrambled-sequence controls to ODN 2009 were as follows: sc-12, 5'TCCCACCTCACCTACATCCG-3'; sc-21, 5'-ACACCCCAATTCTTCCGCCC-3'; and sc-48, 5'-CTCATTCCTACCGACACCCC-3'.

In addition, two 18-mer phosphorothioate ODNs analyzed in a previous study (18) were used for comparison. One was targeted to the translation initiation site of the bcl-2 messenger RNA, and the second corresponded to the scrambledsequence control. The sequences were as follows: atg, 5'-GTGCGCCATCCTTCCCAG-3'; and sc-31, 5'-CGCCAGTCTTGGCTCACC-3'. Of all ODNs, two to three (ODN 2009) different batches were prepared and tested. ODNs were kept at $-20{ }^{\circ} \mathrm{C}$ in $10 \mathrm{~m} M$ Tris (pH 7.4) and $1 \mathrm{~m} M$ ethylenediaminetetraacetic acid.

Treatment of cells with ODNs. ODNs were delivered to cells in the form of complexes with the cationic lipid $N$-[1-(2,3-dioleoyloxy)propyl]- $N, N, N$ trimethylammonium methylsulfate (DOTAP) (Boehringer Mannheim GmbH, Germany). Equal volumes of ODNs $(6 \mu M)$ and DOTAP $(0.2 \mathrm{mM})$ in HEPESbuffered saline were mixed and allowed to form a complex for 10 minutes at room temperature. The mixture was diluted into 9 volumes of RPMI-1640 culture medium without FCS and added to cells in culture medium containing $10 \%$ FCS to a final density of $2 \times 10^{5}$ cells $/ \mathrm{mL}$. The final concentrations were 0.15 $\mu M$ ODNs and $5 \%$ FCS. Controls were treated with equivalent concentrations of DOTAP or medium alone. Cells were incubated at $37^{\circ} \mathrm{C}$ for different periods of time, depending on the experiment. For higher ODN concentrations, the molar ratio of DOTAP to ODN was held constant. In all experiments, different batches of the ODNs were tested.

Measurement of cytotoxicity. The cytotoxicity of ODNs in small-cell lung cancer cells was determined by measurement of cell viability by use of a colorimetric assay, based on the cleavage of the tetrazolium salt WST-1 (Boehringer Mannheim $\mathrm{GmbH}$ ) by mitochondrial dehydrogenases in viable cells (19). For each treatment, $100 \mu \mathrm{L}$ of the mixture of cells and ODNs was plated in triplicates in 96-well plates. ODN concentrations and cell densities were as described above. Cells were incubated for 96 hours at $37^{\circ} \mathrm{C}$, and then $10 \mu \mathrm{L}$ of the WST-1 reagent was added per well and allowed to react for 3 hours at $37^{\circ} \mathrm{C}$. Absorbance at $450 \mathrm{~nm}$ was measured by use of an enzyme-linked immunosorbent assay reader (2550 EIA reader; Bio-Rad Laboratories Ltd., Hercules, CA).

Detection of bcl-2 messenger RNA by northern blot analysis. Total RNA was prepared from $6 \times 10^{6}$ cells by use of the one-step acid guanidinium isothiocyanate extraction method (20). For each sample, $10 \mu \mathrm{g}$ of total RNA was subjected to electrophoresis on denaturing formaldehyde-agarose gels and transferred to nylon membranes (Schleicher and Schuell GmbH, Dassel, Germany) according to standard procedures (21). Membranes were hybridized overnight at $42{ }^{\circ} \mathrm{C}$ with an EcoRI restriction fragment composed of nucleotides 1410 to 2340 of the bcl-2 complementary DNA, which had been radiolabeled with ${ }^{32} \mathrm{P}$ by use of random hexanucleotide primers (Megaprime DNA labeling systems; Amersham International, Little Chalfont, U.K.). Simultaneous hybridization with a 1.3-kilobase (kb) EcoRI/HindIII restriction fragment of the 3.93-kb full-length chicken $\beta$-actin cloned into plasmid pUC9 as described (22) was used as probe for reference. Blots were exposed to a storage phosphor screen scanned by use of a phosphorimager (Molecular Dynamics, Sunnyvale, CA). Relative messenger RNA levels were quantified by use of the ImageQuant software (Molecular Dynamics).

Detection of Bcl-2 protein by western blot analysis. For each treatment, 10 $\mathrm{mL}$ of the mixture of cells and ODNs was plated in a $25-\mathrm{cm}^{2}$ flask and incubated for 24 hours at $37^{\circ} \mathrm{C}$. ODN concentrations and cell densities were as described above. Soluble protein extracts were prepared as described previously (23), and protein concentrations were determined by use of the BCA protein assay reagent (Pierce Chemical Co., Rockford, IL). One hundred micrograms of soluble protein per sample was separated on a $12 \%$ polyacrylamide-sodium dodecyl sulfate gel at $50 \mathrm{~V}$ for about 16 hours. Electrotransfer to a polyvinylidene fluoride membrane (Hybond-PVDF; Amersham International) was performed in a semidry blotting chamber (Schleicher and Schuell) at $1 \mathrm{~mA} / \mathrm{cm}^{2}$ for 1 hour. The blots were blocked in Tris-buffered saline containing $5 \%$ bovine serum albumin and $5 \%$ non-fat milk and then incubated overnight at $4{ }^{\circ} \mathrm{C}$ with $200 \mathrm{ng} / \mathrm{mL}$ mouse anti-human Bcl-2 monoclonal antibody (Dako Diagnostics AG, Glostrup, Denmark). To detect the primary antibody, we incubated blots with a rabbit antimouse immunoglobulin peroxidase conjugate (Sigma Chemical Co., St. Louis, MO) for 2 hours at room temperature. The immunocomplex was visualized by enhanced chemiluminescence by use of the ECL kit (Amersham International), followed by exposure to x-ray film (Fuji RX). Relative protein levels were 
quantified after the films were scanned with a flat bed scanner (Hewlett Packard ScanJet IIcx) and the ImageQuant software.

Detection of apoptotic cells based on light scattering and DNA fragmentation. Apoptotic cells were identified by flow cytometric analysis of DNA fragmentation after the nuclei were stained with propidium iodide in the presence of ribonuclease A (Boehringer Mannheim) as described previously (24) and by simultaneous analysis of cell morphology based on light scattering (25). Briefly, approximately $0.2 \times 10^{6}$ of ODN-treated cells were fixed in $2 \%$ paraformaldehyde and then made permeable in $0.05 \%$ Triton X-100 (Sigma Chemical Co.). Cells were resuspended in $0.5 \mathrm{~mL}$ of $50 \mu \mathrm{g} / \mathrm{mL}$ propidium iodide in phosphatebuffered saline (PBS) and incubated in the dark for 15 minutes at room temperature. Cells were analyzed by use of a FACSCalibur cytofluorometer (Becton Dickinson, Mountain View, CA) equipped with a 4-log-decade full-scale amplifier gain and an analogue-to-digital converter with 1024 channels.

Determination of viable cell numbers by propidium iodide exclusion and light-scattering properties. All cells in the culture were harvested and briefly trypsinized and resuspended in PBS. Immediately before measurement, propidium iodide was added to a final concentration of $10 \mu \mathrm{g} / \mathrm{mL}$, and the number of viable cells was measured by flow cytometric analysis during 2 minutes at a constant flow rate. Based on their morphology, cells were considered intact if they localized to the lower right quadrant of the contour plot (25). Within this region, only cells that excluded propidium iodide were considered viable.

Fluorescent microscopy. Untreated SW2 control cells and SW2 cells treated with $0.45 \mu M$ ODN 2009 for 72 hours were trypsinized, fixed in $2 \%$ paraformaldehyde (Sigma Chemical Co.), and then made permeable in $0.05 \%$ Triton $\mathrm{X}-100$. After being washed with PBS, cells were stained with $5 \mu \mathrm{g} / \mathrm{mL}$ acridine orange (Sigma Chemical Co.) in PBS and analyzed by use of a Leitz DM RXE fluorescence microscope (Leica, Wetzlar, Germany).

Statistical analysis. Data represent the means $\pm 95 \%$ confidence intervals (CIs) of three or four independent determinations. The cytotoxic effect of the antisense ODNs on SW2 cells and the reduction in Bcl-2 protein levels were compared with those of the untreated control by use of the Behrens-Fisher-type $t$ test with unpooled variances. Since multiple comparisons were performed, Bonferroni's inequality was implemented for each comparison to control for the overall type 1 error rate. For example, if the 16 different treatments in the cytotoxicity screening experiment were compared with the control, statistical significance for an individual treatment would be determined by a $P$ value of less than $.05 / 16(=.0031)$. Regression analysis was performed to test for correlation at the .05 significance level between the relative bcl-2 messenger RNA and Bcl-2 protein levels in the cell lines and between the relative levels of Bcl-2 protein and the sensitivity of the cell lines to antisense treatment. Correlation was considered significant at $P<.05$. All $P$ values resulted from the use of two-sided tests.

\section{Results}

\section{Basal Levels of Bcl-2 Expression in Small-Cell Lung Cancer Cell Lines}

Up to $90 \%$ of small-cell lung cancer tumors and cell lines have been shown to express the Bcl-2 protein $(4,12)$. To examine the correlation between bcl-2 transcript and protein expression in additional small-cell lung cancer cell lines, northern and western blot analyses were performed. As shown in Fig. 1, A, bcl-2 messenger RNA was expressed in all cell lines, and NCI-H82 and SW2 cells displayed the highest levels (109\% and 100\%, respectively). However, Bcl-2 protein levels did not correlate with messenger RNA expression in the cell lines (correlation coefficient $r=-.564 ; P=.436)$. Bcl-2 could be readily detected in SW2 cells (100\%) and in NCI-H69 cells (174\%) (Fig. $1, \mathrm{~B})$, whereas faint bands could be seen in NCI-H82 cells (27\%) and NCI-N417 cells (13\%) only after overexposure of the film (Fig. 1, B; lower panel). In the latter cell lines, the levels of Bcl-2 protein were at the detection limit of western blot analysis. SW2 cells were used in subsequent experiments because they expressed intermediate levels of $\mathrm{Bcl}-2$ protein that were readily detectable.

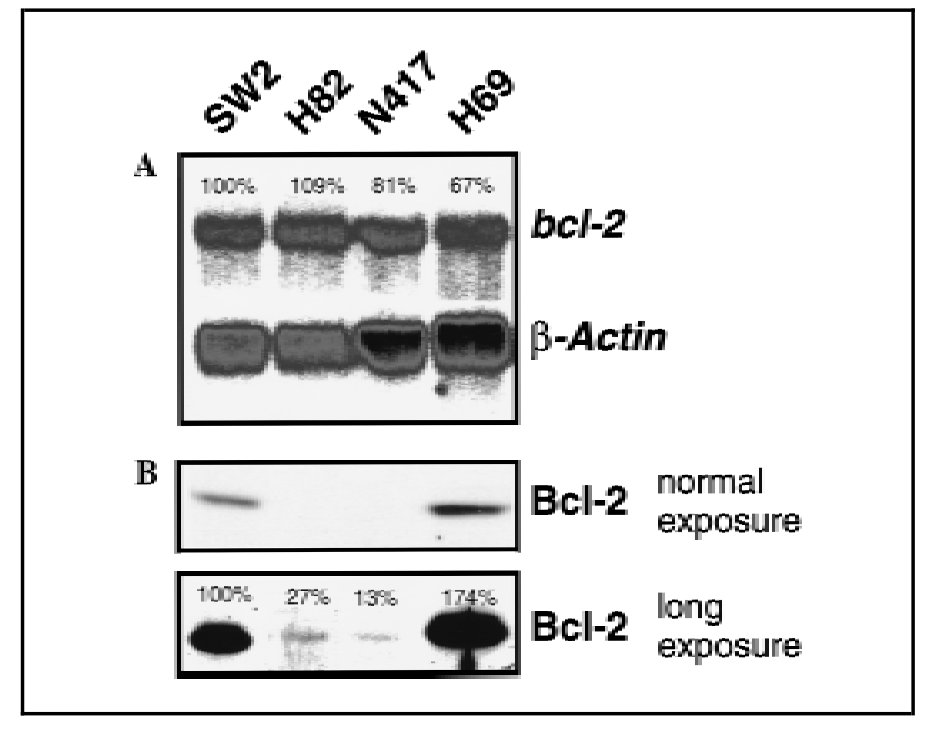

Fig. 1. Detection of bcl-2 expression in the following four human small-cell lung cancer cell lines by northern and western blot analyses: SW2, NCI-H82 (H82), NCI-N417 (N417), and NCI-H69 (H69). For each cell line, $10 \mu \mathrm{g}$ of total RNA was subjected to northern blot analysis and $100 \mu \mathrm{g}$ of soluble protein was subjected to western blot analysis, as described in the "Materials and Methods" section. Northern blots were simultaneously hybridized with bcl-2 and $\beta$-actin probes. Cell lines are indicated at the top of the figure. A) Northern blot; B) western blot. Upper panel: normal exposure. Lower panel: long exposure. Numerical values represent the relative levels of messenger RNA corrected for the amount of $\beta$-actin messenger RNA and of Bcl-2 protein in the cells expressed as the SW2 cell's integrated volume, which was quantified after the autoradiographs were scanned as described in the "Materials and Methods" section.

\section{Different Cytotoxic Effects on SW2 Cells Shown by Antisense ODNs Targeting Different Regions of the bcl-2 Messenger RNA}

Most studies aimed at reducing Bcl-2 protein levels have used antisense ODNs targeting the translation initiation site of the bcl-2 messenger RNA, whereas the $5^{\prime}$ end comprising the 7-methylguanosine residue linked to a triphosphate (5' cap) or the $3^{\prime}$ untranslated region proved most effective in downregulating the expression of other genes. Since it is not possible to predict the effectiveness of an antisense ODN solely on the basis of the two-dimensional structure of the target messenger RNA, it has been proposed that up to 50 antisense ODNs be tested to find a potent inhibitor (26). Our previous results (18) suggested that an antisense 18-mer (ODN atg) directed against the initiation site (i.e., the region containing the initiation codon of the translated sequence) of the bcl-2 messenger RNA could decrease the proliferation of SW2 cells. To assess whether other antisense ODNs might be more cytotoxic for small-cell lung cancer cells, we synthesized thirteen 20-mer phosphorothioates directed against the $5^{\prime}$ untranslated region, the translation initiation site, the coding region, the translation termination site, and the $3^{\prime}$ untranslated region of the bcl-2 messenger RNA. These ODNs were tested for their effect on SW2 cells by use of the WST-1 cell viability assay. ODNs were delivered intracellularly with the aid of the cationic lipid DOTAP. Cells were incubated for 96 hours with $0.15 \mu M$ ODN; controls received medium alone or $5 \mathrm{~m} M$ DOTAP.

As shown in Fig. 2, several antisense ODNs affected cell viability. The 18-mer (ODN atg) caused a statistically significant 
Fig. 2. Cytotoxic effect of antisense oligodeoxynucleotides (ODNs) targeting different regions of the bcl-2 messenger RNA on SW2 cells. Cells were treated for 96 hours with medium alone (control), $5 \mathrm{mM}$ of the transfection reagent $N$-[1-(2,3-dioleoyloxy)propyl]- $N, N, N$ trimethylammonium methylsulfate (DOTAP), or $0.15 \mu M$ of each ODN. Cell viability was determined in triplicate cultures by use of the WST-1 reagent as described in the "Materials and Methods" section. Values are expressed as percent of the control's absorbance at $450 \mathrm{~nm}$. ODNs were directed against the $5^{\prime}$ untranslated region (ODN 2293), the start site (ODNs atg [ATG], 2291, and 2292), the coding region (ODNs 2294 and 2009), the stop codon (ODNs 2295 and 2011), and the $3^{\prime}$ untranslated region (ODNs 2296, 2297, 2298, 2299, 2300, and 2017) of the bcl-2 messenger RNA. ODN sc-31 has the same base composition as ODN atg, but in scrambled order. Data represent the mean values $\pm 95 \%$ confidence intervals $(n=3)$. Significance was determined by a $P$ value $<.0031$. The arrangement of the ODNs along their location relative to the open reading frame of the bcl-2 messenger RNA is shown at the bottom.

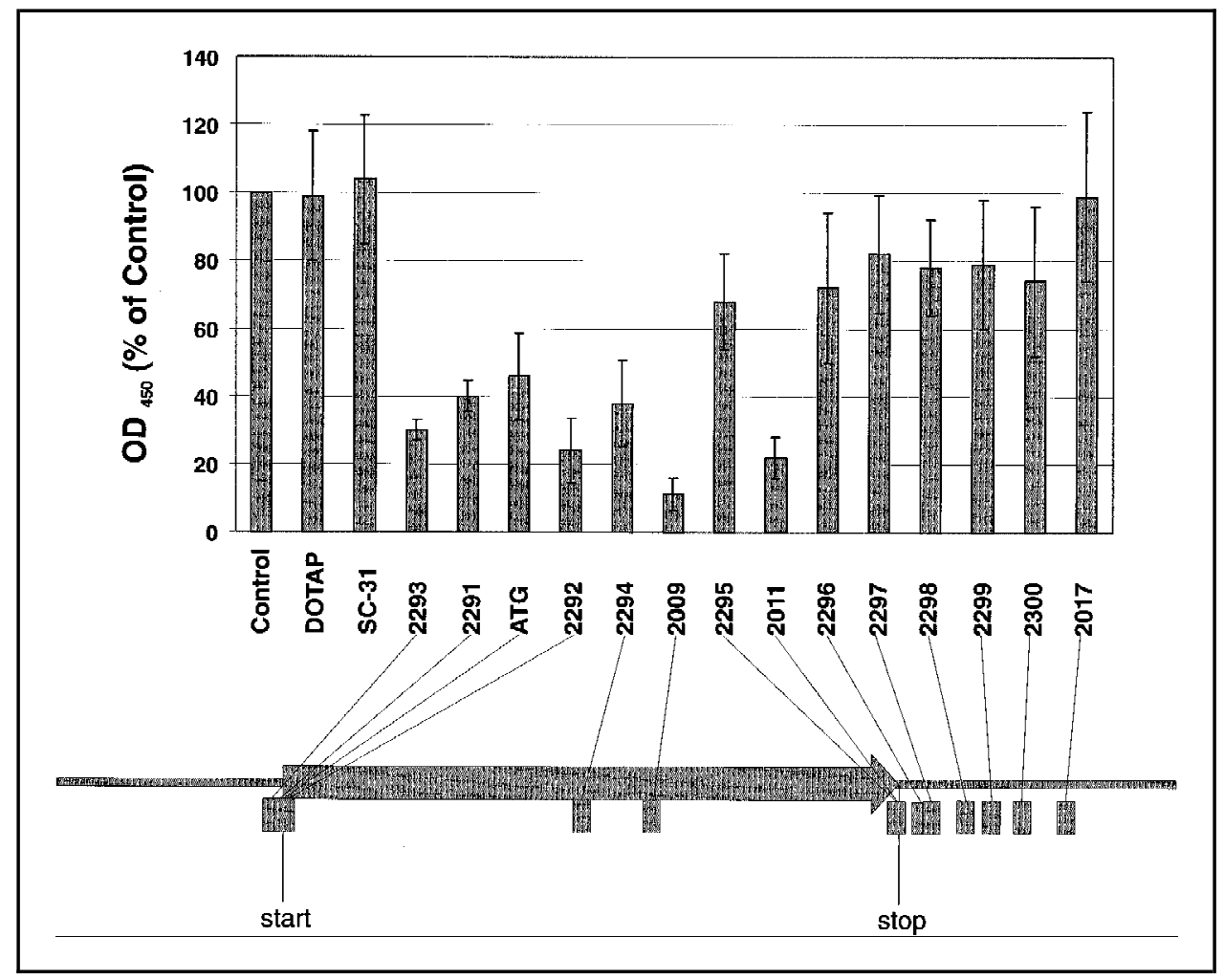

reduction to $47 \%(95 \% \mathrm{CI}=35 \%-59 \%)$, whereas a scrambledsequence control ODN (sc-31) with the same base composition did not change the activity measured by the WST-1 reagent. The 20-mer ODN 2292 directed against the initiation site was more cytotoxic than the corresponding 18-mer (ODN atg), and substantial cytotoxicity was also achieved by two ODNs targeting the $5^{\prime}$ untranslated region (ODN 2293) and the termination site (ODN 2011), respectively. However, ODN 2009, which targets codons 141-147 of the bcl-2 messenger RNA, was the most cytotoxic of all ODNs tested, in that it reduced cell viability to $10 \%(95 \% \mathrm{CI}=5 \%-15 \%)$ relative to that of control-treated cells. A smaller or no effect was seen for all ODNs directed against the 3' untranslated region (ODNs 2296-2300 and ODN 2017) and for the ODNs against the coding region (ODN 2294) and against the termination site (ODN 2295), respectively. This observation suggests that antisense ODNs directed against regions other than the initiation site might be more effective inhibitors of small-cell lung cancer growth.

\section{Rapid and Persistent Reduction in Bcl-2 Protein Levels Induced by ODN 2009}

Nonspecific toxicity of antisense ODNs remains a major problem. Thus, sequence-specific down-regulation of the target protein or messenger RNA has to be demonstrated. We therefore performed western blot analysis to detect Bcl-2 protein levels after treatment of SW2 cells with antisense ODNs. Northern blot analysis was not used because of its insufficient sensitivity, since bcl-2 messenger RNA levels were relatively low (Fig. 1). Only those ODNs were tested that had an effect on SW2 cell viability. Cells were incubated for 4,12 , and 24 hours with either $0.15 \mu M$ ODN, $5 \mathrm{~m} M$ DOTAP, or medium alone. As determined by quantification of the relative protein levels from the x-ray films, none of the antisense ODNs reduced Bcl-2 levels at time points earlier than 24 hours after transfection (data not shown).

As shown in Fig. 3, A, after 24 hours, ODN 2009 caused a visible reduction in Bcl-2. ODN 2011, which targets the translation termination site, caused a similar reduction. In contrast, all other ODNs tested showed little or no reduction in Bcl-2 at that time point. Since the Bcl-2 protein has a half-life of about 10-12 hours (17), the other ODNs might cause a reduction at later time points. To test this possibility, we performed western blot analysis after we incubated the cells for 96 hours under the same conditions. At that time, only ODN 2009 still caused a marked reduction in Bcl-2 levels (Fig. 3, B). Quantification of the relative protein levels in Fig. 3 shows that ODN 2009 significantly reduced Bcl-2 to $18 \%(95 \% \mathrm{CI}=13 \%-23 \%)$ at 24 hours and to $49 \%(95 \% \mathrm{CI}=39 \%-59 \%)$ at 96 hours compared with the control; a statistically significant reduction to $34 \%$ (95\% CI $=$ 26\%-42\%) was also measured for ODN 2011 at 24 hours. All other ODNs caused smaller reductions in the level of Bcl-2 at 24 hours, which were statistically significant $(P<.02)$, and showed no effects at 96 hours. Although we cannot exclude that our ODNs against the translation initiation site might reduce Bcl-2 protein levels at points between 24 hours and 96 hours, our results suggest that ODN 2009 causes the strongest and most persistent reduction in expression of Bcl-2. For this reason, further experiments focused on ODN 2009; ODN 2011 was not studied further because of its lower cytotoxic effect and its shortlasting down-regulation of bcl-2 expression.

To provide further evidence for the sequence-specific action of ODN 2009, three different control ODNs were synthesized with the same base composition but in scrambled order. A BLASTN search of a database containing all sequences of GenBank, EMBL, DDBJ, and PDB revealed no homology of the scrambled-sequence ODNs to human genes (data not shown). To 
Fig. 3. Western blot analysis of Bcl-2 protein in SW2 cells after treatment with antisense oligodeoxynucleotides (ODNs). Cells were incubated for 24 hours (A) or 96 hours (B) with medium alone (control), $5 \mathrm{mM} \mathrm{N}$-[1-(2,3dioleoyloxy)propyl]- $N, N, N$ trimethylammonium methylsulfate (DOTAP), or $0.15 \mu M$ of each ODN; $100 \mu \mathrm{g}$ of soluble protein was analyzed per sample, and western blotting was performed as described in the "Materials and Methods" section. Treatments are indicated at the top of the figure. Mean values and $95 \%$ confidence intervals from 3 experiments are presented.

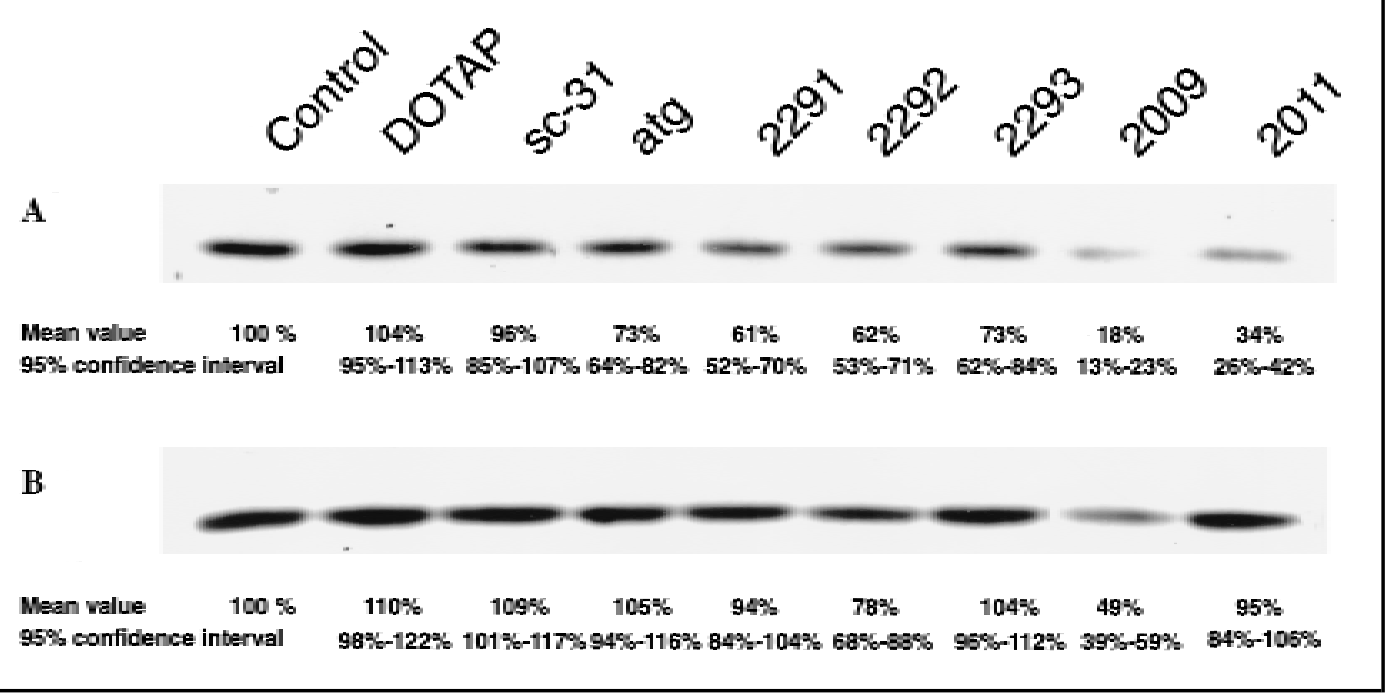

test their effect, we incubated SW2 cells for 24 hours with medium alone, DOTAP ( $5 \mathrm{~m} M, 10 \mathrm{~m} M$, and $15 \mathrm{~m} M)$, or ODNs $(0.15 \mu M, 0.30 \mu M$, and $0.45 \mu M)$. As shown in Fig. 4, the control ODNs (sc-12, sc-21, and sc-48) did not alter Bcl-2 levels. ODN sc-12 could not be tested at the highest dose because the stock solution was too diluted. Similarly, DOTAP showed no effect at either concentration. In contrast, ODN 2009 caused a dose-dependent reduction in Bcl-2. Quantification of relative protein levels revealed reductions of $60 \%, 70 \%$, and $77 \%$ for ODN 2009 at $0.15 \mu M, 0.30 \mu M$, and $0.45 \mu M$, respectively (data not shown). Comparable results were obtained when the same concentrations of ODNs were tested for their effect on the viability of SW2 cells (data not shown). WST-1 assays were performed as described above after SW2 cells had been incubated for 96 hours with the different ODNs. ODN 2009 caused a dose-dependent reduction in cell viability, whereas the scrambled-sequence controls were not toxic. Taken together, these results provide strong evidence for the ability of ODN 2009 to reduce Bcl-2 levels and cell viability of SW2 small-cell lung cancer cells by a sequence-specific mechanism.

\section{Dose-Dependent Apoptosis in SW2 Cells Induced by ODN 2009}

In leukemia cell lines, down-regulation of bcl-2 expression has been shown to reduce cell viability by induction of apoptosis
(16). To test whether this observation applied also to small-cell lung cancer cells, flow cytometric analysis was performed to identify apoptotic cells on the basis of their light-scattering properties and DNA fragmentation (25). SW2 cells were treated for 72 hours with medium alone, DOTAP (5 mM, $10 \mathrm{~m} M$, and 15 $\mathrm{m} M)$, or ODNs $(0.15 \mu M, 0.30 \mu M$, and $0.45 \mu M)$. After fixation and permeabilization, cells were incubated with propidium iodide and subjected to fluorescence-activated cell sorter analysis.

Fig. 5 shows the results plotted as forward scatter against side scatter, which allows the identification of morphologically intact cells, apoptotic cells, and apoptotic bodies. Control-treated cells localized to the lower right quadrant (Fig. 5, A), and no difference was observed in the contour plots corresponding to DOTAP-treated (Fig. 5, B-D) and ODN sc-48-treated (Fig. 5, E-G) cells, irrespective of the concentrations used. Comparable results were obtained with ODNs sc-12 and sc-21 (data not shown). In contrast, a dose-dependent increase in the fraction of apoptotic cells (upper right quadrant) was induced by ODN 2009 (Fig. 5, H-J). At the highest concentration, only a few morphologically intact cells were detectable. This result indicates that ODN 2009 reduced SW2 cell viability by the induction of apoptosis and that this process was dose dependent.

As shown by fluorescent microscopy in Fig. 6, SW2 cells that
Fig. 4. Western blot analysis of Bcl-2 protein in SW2 cells after treatment with various concentrations of oligodeoxynucleotides (ODNs) 2009 and scrambled sequences. Cells were incubated for 24 hours with medium alone (control), $N$-[1-(2,3-dioleoyloxy)propyl]- $N, N, N$-trimethylammonium methylsulfate (DOTAP) at $5 \mathrm{~m} M, 10 \mathrm{~m} M$, and $15 \mathrm{mM}$, or ODNs at $0.15 \mu M, 0.30 \mu M$, and $0.45 \mu M ; 100 \mu \mathrm{g}$ of soluble protein was analyzed per sample, and western blotting was performed as described in the "Materials and Methods" section. Treatments and concentrations are indicated for each sample. Samples are distributed among two blots because of space limitations; control- and DOTAP-treated samples are included in both blots for reference.

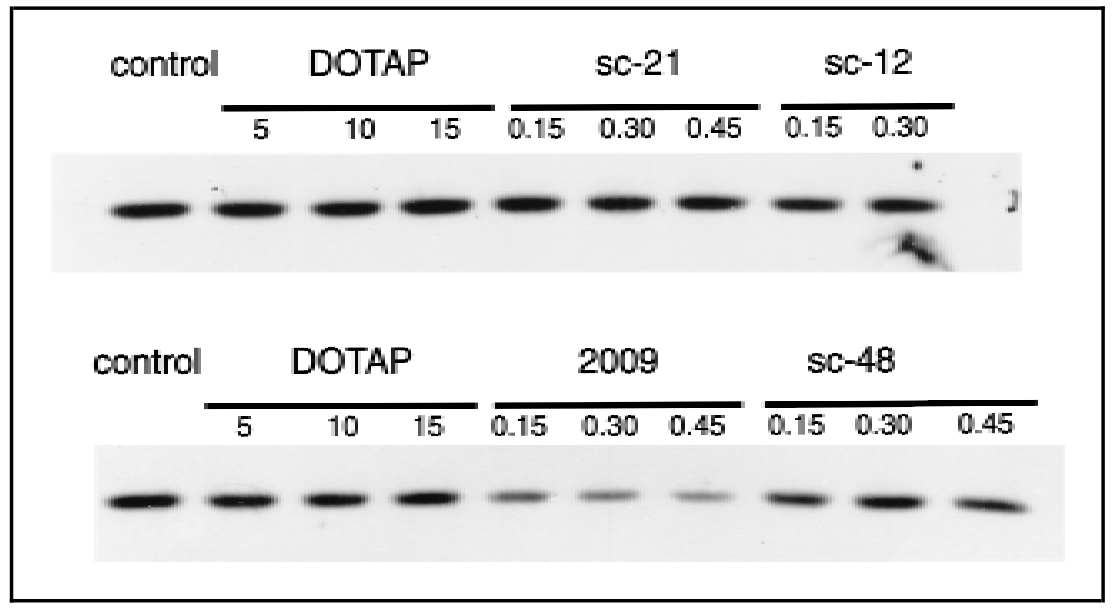


Fig. 5. Morphology of SW2 cells after treatment with oligodeoxynucleotides (ODNs) 2009 and the scrambled-sequence control sc-48. Cells were incubated for 72 hours with medium alone (control), $N$-[1-(2,3-dioleoyloxy)propyl]- $N, N, N$ trimethylammonium methylsulfate (DOTAP) at $5 \mathrm{~m} M, 10$ $\mathrm{m} M$, and $15 \mathrm{~m} M$, or ODNs at $0.15 \mu M, 0.30 \mu M$, and 0.45 $\mu M$ and subjected to flow cytometric analysis. Results are plotted as forward scatter (FSC) against side scatter (SSC). Morphologically normal cells are seen in the lower right quadrant. Treatment and concentrations are listed at the top of each plot. Apoptotic cells are shown in the upper right corner. Panel A: control. Panels B-D: DOTAP. Panels E-G: sc-48. Panels H-J: ODN 2009.
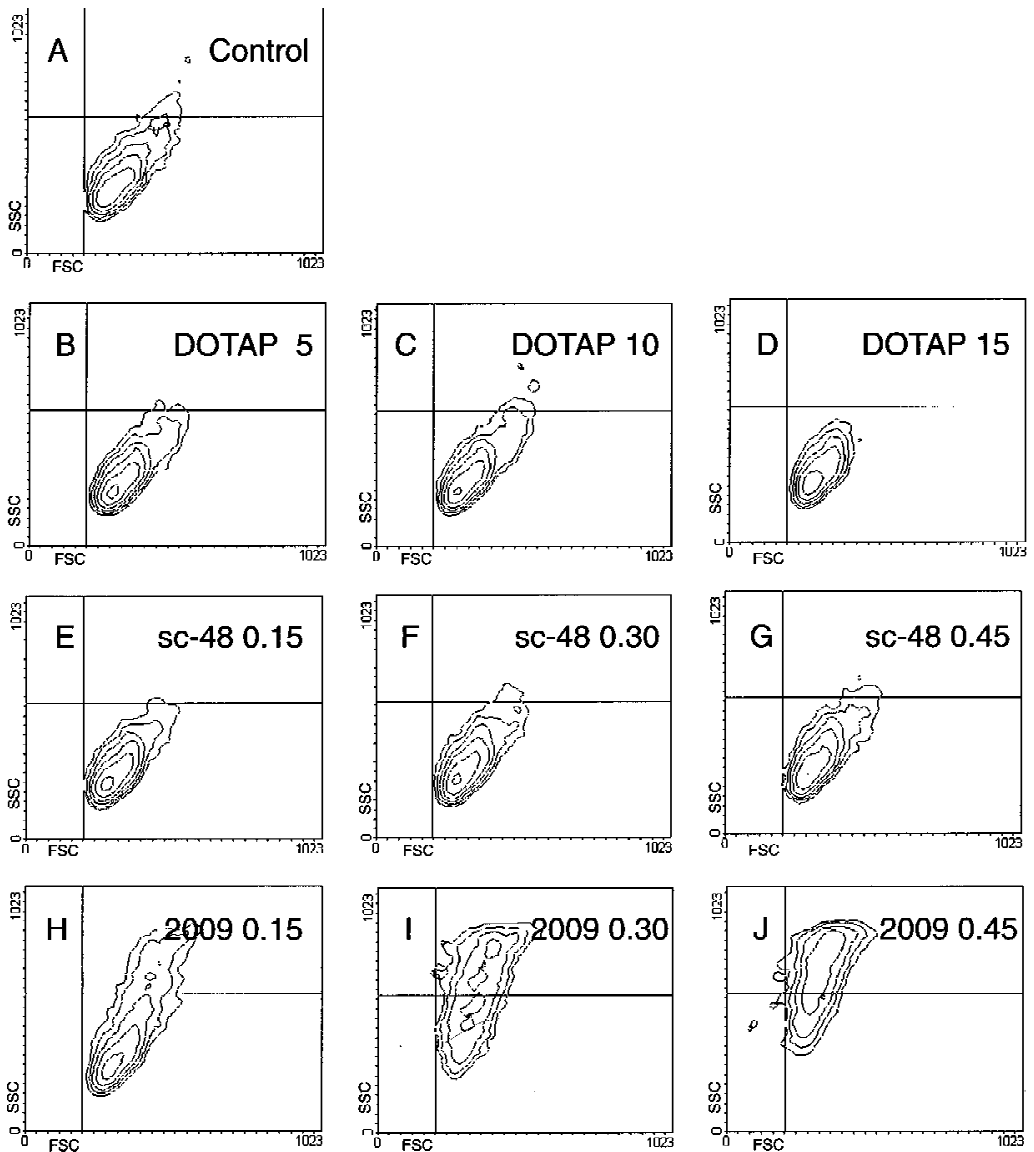

localized to the upper right quadrant after treatment with ODN 2009 exhibited characteristic morphologic features of apoptosis, including nuclear fragmentation into clearly visible apoptotic bodies. This increase in granularity of the cells coincided with the increase in side light scatter intensity shown in Fig. 5, J. In contrast, untreated and ODN sc-48-treated SW2 cells that localized to the lower right quadrant (Fig. 5) were morphologically intact.

Because of incomplete DNA fragmentation, quantification of apoptotic cells based on the pattern of propidium iodide staining (data not shown) did not reflect the strong apoptotic effect of ODN 2009 detected by light-scattering analysis. In the untreated control, $0.8 \%$ of apoptotic cells were measured. Depending on the concentration, in DOTAP-treated and sc-48-treated cells, values ranged from $0.8 \%$ to $0.9 \%$ and from $1.1 \%$ to $1.4 \%$, respectively, indicating a minimal effect. Treatment with ODN 2009 increased the mean percentage of cells displaying fragmented DNA to $2.3 \%$ at $0.15 \mu M, 5.9 \%$ at $0.30 \mu M$, and $8.2 \%$ at $0.45 \mu M$, confirming the dose dependence of this process. A possible explanation for the difference in apoptotic rates determined by DNA fragmentation and light-scattering analysis might be the lack of internucleosomal DNA degradation, which has been reported for epithelial cells (27). Therefore, to obtain more accurate values of viability, we examined cells for their ability to exclude propidium iodide. Quantitation was done by fluorescence-activated cell sorter analysis after 24, 48, 72, and 96 hours of incubation with two different concentrations of ODNs. ODN 2292 was included for comparison.
Fig. 6. Fluorescent micrograph of SW2 cells after staining with acridine orange. A) Untreated SW2 cells. B) SW2 cells treated with $0.45 \mu M$ oligodeoxynucleotide (ODN) sc-48 for 72 hours. C) SW2 cells treated with 0.45 $\mu M$ ODN 2009 for 72 hours. Note the nuclear fragmentation of ODN 2009-treated cells into apoptotic bodies, which coincides with the increase in side light scatter intensity shown in Fig. 5, J (original magnification $\times 1000$ ).

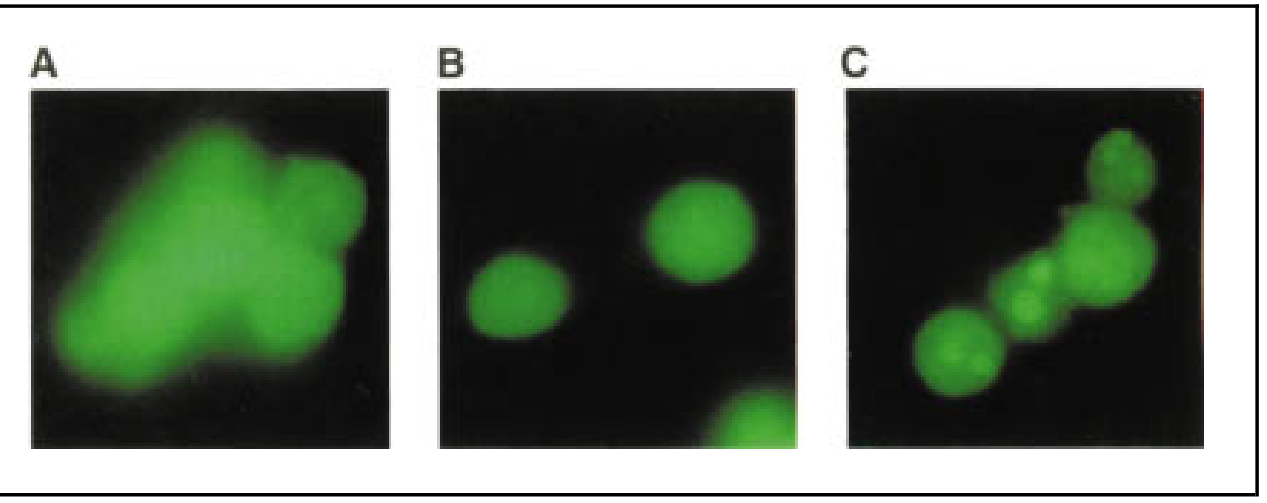


As shown in Fig. 7, ODN 2009 strongly inhibited cell growth, which was apparent already after 48 hours. Moreover, at the highest concentration $(0.30 \mu M)$, ODN 2009 completely abolished cell proliferation, as shown by the steady decrease in the number of viable cells (Fig. 7, B). ODN 2292 also inhibited cell growth, but to a lesser degree than ODN 2009. At 96 hours, the difference between the effects of these ODNs was highly significant $(P<.01)$. Furthermore, ODN 2292 appeared to have only a transient effect even at high concentrations, since proliferation rates began to recover after 72 hours. The number of viable cells was reduced to $28 \%(95 \% \mathrm{CI}=20 \%-36 \%)$ and $5 \%(95 \% \mathrm{CI}=$ $2 \%-8 \%$ ) of control values after 96 hours of treatment with 0.15 $\mu M$ and $0.30 \mu M$ ODN 2009, respectively. In agreement with the results obtained by light-scattering analysis (Fig. 5), our findings confirm that ODN 2009 causes extensive apoptosis of SW2 cells.

\section{Cytotoxicity of ODN 2009 on Various Small-Cell Lung Cancer Cell Lines}

The results described so far have demonstrated the potent cytotoxic effects of ODN 2009 on a single cell line, SW2. Therefore, using the WST-1 assay, we examined the cytotoxic effect of ODN 2009 on three other small-cell lung cancer cell lines (NCI-H82, NCI-H69, and NCI-N417), all of which reveal different basal levels of Bcl-2 protein (Fig. 1). Cells were incubated for 96 hours with either medium alone, $5 \mathrm{mM}$ DOTAP, or 0.15 $\mu M$ ODNs.

As shown in Fig. 8, ODN 2009 was cytotoxic to all cell lines tested, but sensitivities varied among the cell lines. NCI-H69 and SW2 cells were the most resistant, their viability being reduced to $18 \%(95 \% \mathrm{CI}=14 \%-22 \%)$ and $9 \%(95 \% \mathrm{CI}=$ $6 \%-12 \%)$, respectively, of the untreated control value after treatment with ODN 2009. In contrast, no viable NCI-H82 and NCIN417 cells could be detected, and morphologic analysis revealed no evidence of living cells (data not shown). This result demonstrates that the cytotoxic effect of ODN 2009 was highly specific and inversely correlated $(r=-.9964 ; P=.003)$ with basal levels of Bcl-2 in small-cell lung cancer cells and that their survival depends on the protective function of this protein.

\section{Discussion}

The emergence of resistance to chemotherapeutic agents remains a major problem in the treatment of patients with smallcell lung cancer, despite the fact that these patients usually have a good initial response to chemotherapy. Although a number of genetic alterations associated with drug resistance in small-cell lung cancer are known, including the deregulated expression of proteins involved in drug transport and activity (2), and in cell cycle checkpoint control (28), few advances have been made in improving the therapeutic options. The Bcl-2 protein can block apoptosis by most chemotherapeutic agents $(10,11)$, as has also been corroborated in small-cell lung cancer cells after ectopic expression (13). Thus, in view of the prevalence of elevated Bcl-2 expression in small-cell lung cancer, one might hypothesize that Bcl-2 must be vital for small-cell lung cancer cells. In our study, we have addressed this issue by using antisense ODNs to down-regulate bcl-2 expression in small-cell lung cancer cells and to examine the consequences of disrupted bcl-2 expression on the viability of small-cell lung cancer cells.

Early studies in cell-free systems suggested that antisense ODNs be targeted to single-stranded rather than to doublestranded regions of the RNA for optimal binding and that ODN length should be kept to a minimum (29). In living cells, however, finding an antisense ODN with optimal properties has proved to be a rather empirical task. Hence, antisense ODNs targeting the $5^{\prime}$ end proved most effective for the downregulation of expression of c-myc (30), c-Ha-ras (31), and rabbit globin (32), whereas a $3^{\prime}$ untranslated region sequence was a better target for down-regulation of c-raf expression (33). Antisense ODNs targeting the translation initiation site have been used for other genes, but screening studies were not always performed to ensure an optimal effect. So far, sequences in the coding region have not yet been shown to be useful targets. In our study, we tested thirteen 20-mer phosphorothioates directed against the $5^{\prime}$ untranslated region, the translation initiation site, the coding region, the translation termination site, and the $3^{\prime}$ untranslated region of the bcl-2 messenger RNA. A gene bank search revealed no homology of the antisense ODNs to genes other than bcl-2, except for ODN 2300, which, however, did not

Fig. 7. Determination of viable SW2 cell numbers by light-scattering analysis and propidium iodide exclusion. Cells were incubated with medium alone (control), $N$-[1-(2,3-dioleoyloxy)propyl]$N, N, N$-trimethylammonium methylsulfate (DOTAP), or oligodeoxynucleotides (ODNs). Viable cells were quantitated by flow cytometric analysis on the basis of cell morphology and propidium iodide staining at 24, 48, 72, and 96 hours as described in the "Materials and Methods" section. Data represent mean values $(\mathrm{n}=4)$. A) 5 $\mathrm{m} M$ DOTAP and $0.15 \mu M$ ODNs. Mean viable cell number in untreated control cultures at 96 hours $=125 \times 10^{3}$ cells $/ 100 \mu \mathrm{L}=100 \%$. After 96 hours of treatment with ODN 2009, $36 \times 10^{3}$ cells $/ 100 \mu \mathrm{L}(95 \%$ confidence interval $[\mathrm{CI}]=26$ $\times 10^{3}-45 \times 10^{3}$ cells $\left./ 100 \mu \mathrm{L}\right)$ remain; this corre-

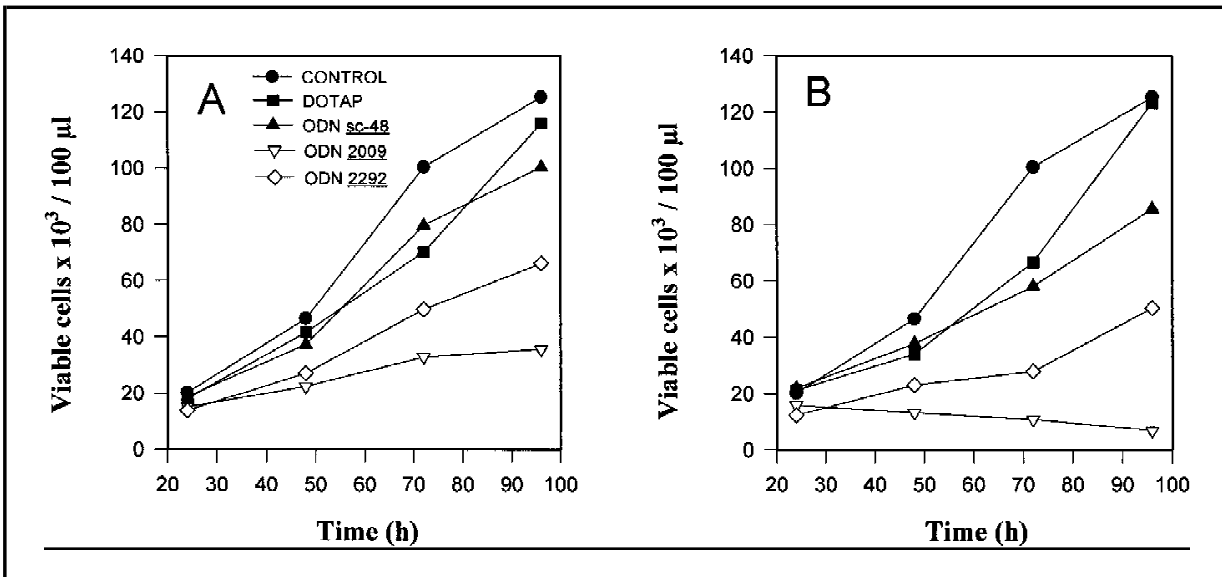
sponds to $28 \%(95 \% \mathrm{CI}=20 \%-36 \%)$ of the con-

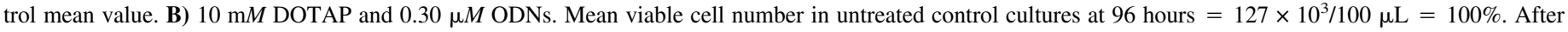

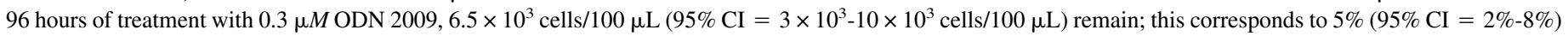
of the control mean value. The $95 \%$ CIs for the other data points did not exceed $15 \%$ and have been omitted for the sake of clarity. 
Fig. 8. Cytotoxic effect of oligodeoxynucleotide (ODN) 2009 and scrambled-sequence ODN sc-48 on various small-cell lung cancer cell lines. Cells were treated for 96 hours with medium alone (control), $5 \mathrm{~m} M$ of the transfection reagent $N$-[1-(2,3-dioleoyloxy)propyl]$\mathrm{N}, \mathrm{N}, \mathrm{N}$-trimethylammonium methylsulfate (DOTAP), or $0.15 \mu M$ of each ODN. Cell viability was determined in triplicate cultures by use of the WST-1 reagent as described in the "Materials and Methods" section. Values are expressed as percent of the control's absorbance at $450 \mathrm{~nm}\left(\mathrm{OD}_{450}\right)$ and represent the means $\pm 95 \%$ confidence intervals $(n=4)$. Solid gray bars $=$ control; open bars = DOTAP; bars with vertical lines $=$ ODN sc48; solid black bars = ODN 2009.

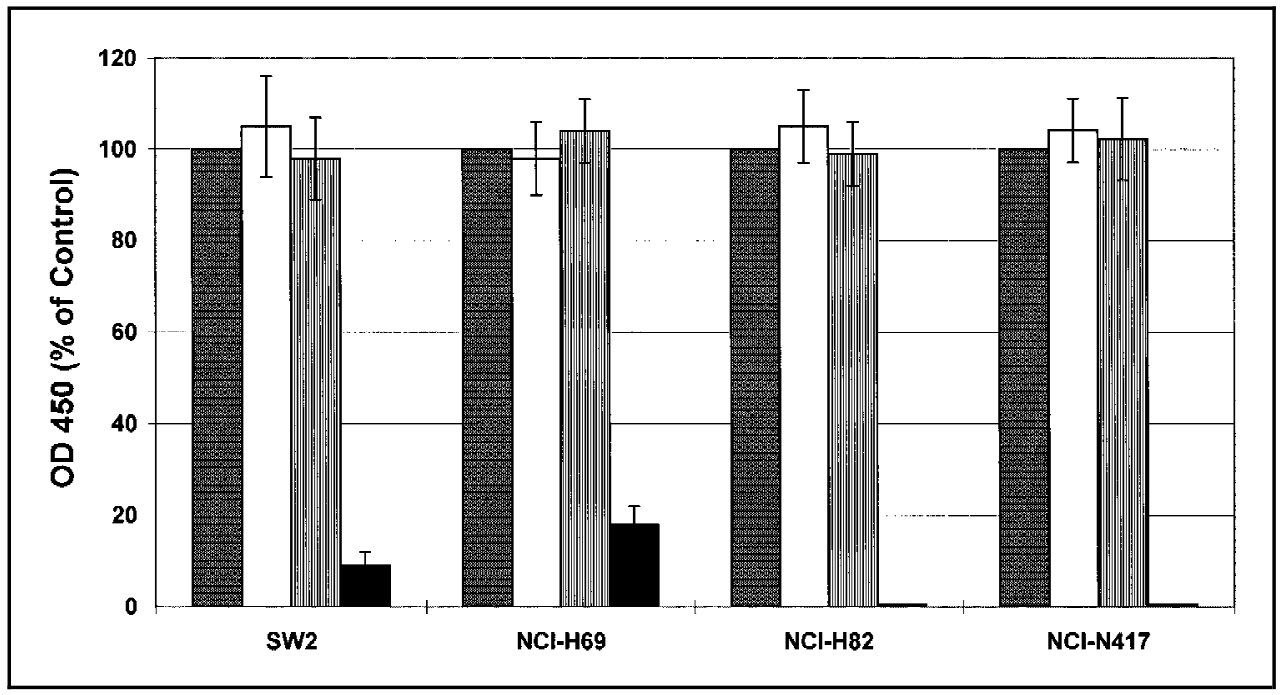

reduce bcl-2 expression. The ODNs were first screened for an effect on small-cell lung cancer cell viability, since preliminary experiments had shown an 18-mer antisense ODN directed against the bcl-2 translation initiation site to be cytotoxic to small-cell lung cancer cells. The results revealed that various antisense ODNs could reduce SW2 cell viability. ODNs directed against the translation initiation and termination sites were roughly equivalent, whereas little or no effect was observed for all ODNs targeting the $3^{\prime}$ untranslated region. It is interesting to note that an 18-mer targeting the translation initiation site, which has recently been shown to efficiently potentiate the cytotoxic effect of doxorubicin on small-cell lung cancer cells (18), was less cytotoxic than a 20-mer to the same region. This observation suggests that reducing ODN length might be deleterious to its effectiveness. An unexpected finding was that an ODN directed against the coding region of the bcl-2 messenger RNA (ODN 2009) was the most cytotoxic. So far, only ODNs targeting the translation initiation site or regions immediately downstream have been shown to down-regulate bcl-2 expression $(15,34)$. Based on the predicted secondary structure of the bcl- 2 messenger RNA, no prominent single-stranded region could be identified at any of the binding sites of the ODNs that had shown an effect on cell viability. This result confirms that, with current tools, it is not possible to predict the effectiveness of an antisense ODN in living cells unless screening experiments are performed.

Establishing that an antisense ODN works through sequencespecific mechanisms has proved to be not only important but also difficult. Indeed, many of the early results obtained with the use of antisense ODNs were later shown to be the consequence of nonspecific ODN toxicity. Usually, the sequence-specific effect of an antisense ODN is inferred from the reduction of the target messenger RNA or protein. In small-cell lung cancer cell lines, we found bcl-2 messenger RNA levels to be relatively low, and demonstration of antisense effects was thus based on Bcl-2 protein measurements. Consistent with the results on cell viability, ODN 2009 caused the strongest down-regulation of Bcl-2 protein. The effect was dose dependent and lasted up to 96 hours. Antisense ODNs targeting the translation initiation site were significantly less potent, and their effect was only transient.
A similar observation was described for lymphoma cells, in which an antisense ODN directed to codons 1 through 6 of the bcl-2 messenger RNA drastically reduced messenger RNA levels but caused only slow and variable reductions in Bcl-2 protein levels $(17,34)$. The delayed response was attributed to the long half-life of Bcl-2 (10-12 hours). This antisense ODN (Anticode G3139) is currently being investigated in a phase I trial in lymphoma patients (35). In contrast to ODNs targeting the translation initiation site of the bcl-2 messenger RNA, ODN 2009 reduced Bcl-2 protein levels to $19 \%$ of the control value within 24 hours, and this effect was reproducible. Three scrambledsequence control ODNs with the same base composition did not alter bcl-2 expression or small-cell lung cancer cell viability, even when they were tested at higher concentrations. These results provide strong evidence for a sequence-specific mechanism of action. It is worth mentioning that, after 96 hours, ODN 2009 still maintained Bcl-2 levels reduced to $50 \%$ of the control value, while all other ODNs failed to show an effect at that time. This persistent action of ODN 2009 might be desirable for two reasons: 1) It is likely to ensure an optimal and long-lasting antisense effect; 2) the fraction of cells surviving antisense treatment might be sensitized toward further cytotoxic damage, e.g., by chemotherapeutic drugs.

It has been shown that DNA fragmentation is not a reliable hallmark of apoptosis in epithelial cells (27). Similarly, we failed to accurately separate apoptotic from viable small-cell lung cancer cells on the basis of their pattern of DNA staining with propidium iodide. In contrast, as reported by Cotter et al. (25), apoptotic cells could be readily identified on the basis of morphologic changes, such as cell shrinkage and increased granularity, which dramatically changed the forward and side light scatter properties of the cells. Using flow cytometric analysis of cell morphology and propidium iodide exclusion, we could demonstrate that ODN 2009 kills small-cell lung cancer cells by a dose-dependent induction of apoptosis. At $0.30 \mu M$ ODN 2009, SW2 cell proliferation was completely inhibited, and the number of viable cells decreased steadily even after 96 hours. Furthermore, ODN 2009 proved to be cytotoxic to three additional small-cell lung cancer cell lines. Surprisingly, we found comparable levels of bcl-2 messenger RNA in the four small- 
cell lung cancer cell lines, although Bcl-2 protein levels were different. Similar observations have been made in normal germinal center B cells $(36,37)$. A recent report (38) suggests that bcl-2 expression can indeed be negatively regulated through translational mechanisms by a cis-acting element located upstream of the normal coding region of the bcl-2 gene. In general, Bcl-2 protein levels in the cell lines and their sensitivity to ODN 2009 were inversely correlated, a finding further confirming the specificity of the effect exerted by this antisense treatment. NCIH69 cells were the most resistant, and SW2 cells showed an intermediate response. In contrast, NCI-H82 and NCI-N417 cells, which revealed barely detectable Bcl-2 levels, were extremely sensitive.

Despite this clear correlation, however, the cytotoxic effect of Bcl-2 reduction was disproportional among the cell lines. By the use of ODN atg, for example, in SW2 cells, reduction of Bcl-2 to $73 \%$ of the normal value decreased the viability to $47 \%$. Thus, SW2 cells could not tolerate reduction of Bcl-2 below a critical threshold, which was still above the basal levels of Bcl-2 found in the sensitive cell lines NCI-H82 and NCI-N417. It is unclear why Bcl-2 appears to be more crucial for the survival of SW2 cells. Our preliminary data suggest that the levels of Bax and Bak are not dramatically different among the cell lines, and Bcl- $\mathrm{x}_{\mathrm{L}}$ levels seem not to be correlated to the cytotoxic effect of Bcl-2 reduction (data not shown). Since the functional regulation and the interplay of pro-apoptotic and anti-apoptotic molecules, such as the interaction of the various Bcl-2 family members, are only partially understood (39), more information will be necessary to understand the molecular basis of our finding.

In conclusion, our results suggest that $\mathrm{Bcl}-2$ is critical for inhibiting apoptosis in small-cell lung cancer cells. With ODN 2009, we have identified a novel antisense sequence that most effectively down-regulates expression of the bcl-2 protooncogene in cells derived from a solid tumor; this sequence deserves further preclinical and clinical investigation.

\section{References}

(1) Ihde DC, Pass HI, Glatstein EJ. Small cell lung cancer. In: DeVita VT Jr, Hellmann S, Rosenberg SA, editors. Cancer: principles and practice of oncology. Vol 1. 4th ed. Philadelphia: Lippincott, 1993:723-58.

(2) Doyle LA. Mechanisms of drug resistance in human lung cancer cells. Semin Oncol 1993;20:326-37.

(3) Takahashi T, Nau MM, Chiba I, Birrer MJ, Rosenberg RK, Vinocour M, et al. p53: a frequent target for genetic abnormalities in lung cancer. Science 1989;246:491-4.

(4) Jiang SX, Sato Y, Kuwao S, Kameya T. Expression of bcl-2 oncogene protein is prevalent in small cell lung carcinomas. J Pathol 1995;177:135-8.

(5) Tsujimoto Y, Croce CM. Analysis of the structure, transcripts, and protein products of bcl-2, the gene involved in human follicular lymphoma. Proc Natl Acad Sci U S A 1986;83:5214-8.

(6) Hockenbery D, Nunez G, Milliman C, Schreiber RD, Korsmeyer SJ. Bcl-2 is an inner mitochondrial membrane protein that blocks programmed cell death. Nature 1990;348:334-6.

(7) Borner C. Diminished cell proliferation associated with the deathprotective activity of Bcl-2. J Biol Chem 1996;271:12695-8.

(8) Shimizu S, Eguchi Y, Kamiike W, Matsuda H, Tsujimoto Y. Bcl-2 expression prevents activation of the ICE protease cascade. Oncogene 1996; 12:2251-7.

(9) Nunez G, Seto M, Seremetis S, Ferrero D, Grignani F, Korsmeyer SJ, et al. Growth- and tumor-promoting effects of deregulated BCL2 in human B-lymphoblastoid cells. Proc Natl Acad Sci U S A 1989;86: 4589-93.
(10) Dole M, Nunez G, Merchant AK, Maybaum J, Rode CK, Bloch CA, et al. Bcl-2 inhibits chemotherapy-induced apoptosis in neuroblastoma. Cancer Res 1994;54:3253-9.

(11) Reed JC, Kitada S, Takayama S, Miyashita T. Regulation of chemoresistance by the bcl-2 oncoprotein in non-Hodgkin's lymphoma and lymphocytic leukemia cell lines. Ann Oncol 1994;5 Suppl 1:61-5.

(12) Ikegaki N, Katsumata M, Minna J, Tsujimoto Y. Expression of bcl-2 in small cell lung carcinoma cells. Cancer Res 1994;54:6-8.

(13) Ohmori T, Podack ER, Nishio K, Takahashi M, Miyahara Y, Takeda Y, et al. Apoptosis of lung cancer cells caused by some anti-cancer agents (MMC, CPT-11, ADM) is inhibited by bcl-2. Biochem Biophys Res Commun 1993;192:30-6.

(14) Cotter FE, Johnson P, Hall P, Pocock C, al Mahdi N, Cowell JK, et al. Antisense oligonucleotides suppress B-cell lymphoma growth in a SCIDhu mouse model. Oncogene 1994;9:3049-55.

(15) Smith MR, Abubakr Y, Mohammed R, Xie T, Hamdan M, al-Katib A. Antisense oligodeoxyribonucleotide down-regulation of bcl-2 gene expression inhibits growth of the low-grade non-Hodgkin's lymphoma cell line WSU-FSCCL. Cancer Gene Ther 1995;2:207-12.

(16) Keith FJ, Bradbury DA, Zhu YM, Russell NH. Inhibition of bcl-2 with antisense oligonucleotides induces apoptosis and increases the sensitivity of AML blasts to Ara-C. Leukemia 1995;9:131-8.

(17) Kitada S, Takayama S, De Riel K, Tanaka S, Reed JC. Reversal of chemoresistance of lymphoma cells by antisense-mediated reduction of bcl-2 gene expression. Antisense Res Dev 1994;4:71-9.

(18) Froesch BA, Luedke GH, Ziegler A, Stahel RA, Zangemeister-Wittke U. The combined application of a doxorubicin immunoconjugate and bcl-2 antisense oligonucleotides on non-resistant and drug resistant small cell lung cancer cell lines. Tumor Targeting. In press.

(19) Cory AH, Owen TC, Barltrop JA, Cory JG. Use of an aqueous soluble tetrazolium/formazan assay for cell growth assays in culture. Cancer Commun 1991;3:207-12.

(20) Chomczynski P, Sacchi N. Single-step method of RNA isolation by acid guanidinium thiocyanate-phenol-chloroform extraction. Anal Biochem 1987;162:156-9.

(21) Sambrook J, Fritsch EF, Maniatis T. Molecular cloning: a laboratory manual. Cold Spring Harbor (NY): Cold Spring Harbor Laboratory Press, 1989:7:43.

(22) Cleveland DW, Lopata MA, MacDonald RJ, Cowan NJ, Rutter WJ, Kirschner MW. Number and evolutionary conservation of $\alpha$ - and $\beta$-tubulin and cytoplasmic $\beta$ - and $\gamma$-actin genes using specific cloned cDNA probes. Cell 1980;20:95-105.

(23) Hanada M, Krajewski S, Tanaka S, Cazals-Hatem D, Spengler BA, Ross RA, et al. Regulation of Bcl-2 oncoprotein levels with differentiation of human neuroblastoma cells. Cancer Res 1993;53:4978-86.

(24) Nicoletti I, Migliorati G, Pagliacci MC, Grignani F, Riccardi C. A rapid and simple method for measuring thymocyte apoptosis by propidium iodide staining and flow cytometry. J Immunol Methods 1991;139:271-9.

(25) Cotter TG, Lennon SV, Glynn JM, Green DR. Microfilament-disrupting agents prevent the formation of apoptotic bodies in tumor cells undergoing apoptosis [published erratum appears in Cancer Res 1992;52:3512]. Cancer Res 1992;52:997-1005.

(26) Wagner RW. The state of the art in antisense research. Nat Med 1995;1: 1116-8.

(27) Oberhammer F, Wilson JW, Dive C, Morris ID, Hickman JA, Wakeling $\mathrm{AE}$, et al. Apoptotic death in epithelial cells: cleavage of DNA to 300 and/or $50 \mathrm{~kb}$ fragments prior to or in the absence of internucleosomal fragmentation. EMBO J 1993;12:3679-84.

(28) Bodner SM, Minna JD, Jensen SM, D’Amico D, Carbone D, Mitsudomi T, et al. Expression of mutant p53 proteins in lung cancer correlates with the class of p53 gene mutation. Oncogene 1992;7:743-9.

(29) Lima WF, Monia BP, Ecker DJ, Freier SM. Implication of RNA structure on antisense oligonucleotide hybridization kinetics. Biochemistry 1992;31: 12055-61.

(30) Bacon TA, Wickstrom E. Walking along human c-myc mRNA with antisense oligodeoxynucleotides: maximum efficacy at the 5' cap region. Oncogene Res 1991;6:13-9.

(31) Daaka Y, Wickstrom E. Target dependence of antisense oligodeoxynucleotide inhibition of c-Ha-ras p21 expression and focus formation in T24transformed NIH3T3 cells. Oncogene Res 1990;5:267-75. 
(32) Blake KR, Murakami A, Miller PS. Inhibition of rabbit globin mRNA translation by sequence-specific oligodeoxyribonucleotides. Biochemistry 1985;24:6132-8.

(33) Monia BP, Johnston JF, Geiger T, Muller M, Fabbro D. Antitumor activity of a phosphorothioate antisense oligodeoxynucleotide targeted against $\mathrm{C}$ raf kinase. Nat Med 1996;2:668-75.

(34) Kitada S, Miyashita T, Tanaka S, Reed JC. Investigations of antisense oligonucleotides targeted against bcl-2 RNAs. Antisense Res Dev 1993;3: 157-69.

(35) Webb A, Cunningham D, Cotter F, Clark P, di Stefano F, Ross P, et al. Bcl-2 antisense therapy in patients with non-Hodgkin lymphoma. Lancet 1997;349:1137-41.

(36) Kondo E, Nakamura S, Onoue H, Matsuo Y, Yoshino T, Aoki H, et al. Detection of bcl-2 protein and bcl-2 messenger RNA in normal and neoplastic lymphoid tissues by immunohistochemistry and in situ hybridization. Blood 1992;80:2044-51.

(37) Chleq-Deschamps CM, LeBrun DP, Huie P, Besnier DP, Warnke RA, Sibley RK, et al. Topographical dissociation of BCL-2 messenger RNA and protein expression in human lymphoid tissues. Blood 1993;81: 293-8.

(38) Harigai M, Miyashita T, Hanada M, Reed JC. A cis-acting element in the BCL-2 gene controls expression through translational mechanisms. Oncogene 1996;12:1369-74.

(39) Vaux DL, Strasser A. The molecular biology of apoptosis. Proc Natl Acad Sci U S A 1996;93:2239-44.

\section{Notes}

Present address: A. Ziegler, Catholic University of Chile, Faculty of Medicine, Department of Hematology/Oncology, Laboratory of Molecular and Cellular Oncology, Santiago.

Supported by the Swiss National Science Foundation (grant B-2006.295.5879) and the Swiss Foundation for Cancer Research (grant AKT 419).

We thank T. Schenker for excellent technical assistance.

Manuscript received January 16, 1997; revised May 8, 1997; accepted May $13,1997$. 